\title{
Measuring and Imaging the Soil-root-water System with a Light Transmission 2D Technique
} Claude Doussan ${ }^{\#, *}$ and Emmanuelle Garrigues $\$$,\#

UMR 1114 EMMAH, INRA/UAPV, Avignon, France; ${ }^{\$}$ Current address: ESA, Angers, France

*For correspondence: claude.doussan@inra.fr

${ }^{\#}$ Contributed equally to this work

[Abstract] Improving crops against water deficits requires a better understanding of plant root system functioning. This requires a better knowledge of the water uptake process and to address the influence of root system architecture or root physiological properties on the uptake efficiency. To this end, we describe here a non-destructive system that enables a dynamic, quantitative, functional imaging of the soil water and of the root system, from the single root to the whole root system scale.

This system is based on plants grown in sandy rhizotrons and relies on the modulation, by soil water content, of the intensity of light transmitted through the rhizotron. Images of the transmitted light during plant water uptake (or release) phases are recorded with a CCD camera and water content can be related to the grey level of image pixels with a calibration.

This system is affordable and can be implemented relatively easily without specific equipment. It is scalable and quick to allow the phenotyping of a range of plant genotypes relative to their water uptake pattern. This pattern can then be related with root system properties (soil colonization, root architecture) at different plant stages. Combined with modeling, imaging results help in getting parameters such as root hydraulic conductivity, distributed root water uptake rates or root xylem water potential. Combination of modeling and experiment further helps in testing biological and physiological assumptions and in predicting the uptake behavior of plants in the field.

Keywords: Imaging, Soil water, Roots, Architecture, Water uptake, Rhizotron

[Background] During decades, detailed observation of water uptake by plant roots, as well as water flux trough roots and plants, has been technically challenging. Most of water uptake studies have been made by measuring soil water content variation with time. In the field, such measurements are based on the use of moisture sensors distributed in soil such as neutron moisture meter (Hignett and Evett, 2002) or electromagnetic TDR or capacitive sensors (Li et al., 2002). In a controlled condition, with potted plants, the weight of the pot can be used to determine pot water content. However, if these kinds of measurements are well suited to describe macroscopic soil water behavior, they do not give access to detailed distribution of water around roots and to the interactions for water between roots. Also, they do not reveal the distribution and functioning of roots.

Concomitantly to moisture measurements in the field, root distribution can be assessed destructively with core samples, trench wall profiling or less destructively with mini-rhizotron imaging (Smit et al., 2000). This gives access to a root distribution (of length, root impacts, biovolume) with depth. The variability in rooting needs generally to acquire a high number of samples, a difficult task as 
sampling/measurements are highly time and labor demanding.

Plant and root hydric relationships can be examined with a variety of measuring devices. Sap flow can be estimated in stems and coarse roots with heat balance sap flow meters (Granier, 1987); root hydraulic conductance can be estimated from root segments to root systems with tension induced measurements (North and Nobel, 1995), root pressure probe (Frensch and Steudle, 1989) or pressure cell (Miyamoto et al., 2001). Root water uptake flux at the single root level can be investigated with potometer (Sanderson, 1983), dye tracing (Varney and Canny, 1993).

All these methods deliver complementary information/properties of the water-soil-plant system, but most of the time, measurements have to be conducted on excised root segments, roots or root systems separated from soil, or for plants grown in hydroponics. They also combine information on roots which might not be similar (e.g., root type, age or order, location within the root system).

Imaging techniques allow the observation of living root systems and their interaction with soil without the need of excising or extracting them from soil. They also enable to quantify root architecture and growth, root type and age if measurements are repeated in time. Ideally, imaging technique shall enable not only root imaging but also other parameters such as water content. Different imaging techniques have been used to investigate the water-soil-root system these last years. They differ in their ability to resolve roots or water, the size of samples, the 2D or 3D description, the tractability and accessibility. Xray scanning was first used in the pioneering work of Hainsworth and Aylmore (1983 and 1986). Since then, X-ray scanners highly increased in resolution, power and scanning speed as did image processing for roots tracking and segmentation in soil columns (Tracy et al., 2010). However, accurately quantifying water and roots in 3D soils is still a challenge (Zappala et al., 2013) as the technique shows almost the same response for water and roots, with a trade-off between resolution and size of the sample (Pierret et al., 2003a and 2003b). X-ray scanners are nowadays more accessible to soil/root researchers, but still not fully accessible and rather expensive. Magnetic resonance imaging (MRI), based on the $\mathrm{H}$ spin relaxation in a magnetic field, has shown high potentials for imaging soil and water (Pohlmeier et al., 2008) because of its high sensitivity to water. However, the rather low resolution necessitates relatively small samples. Some natural soils cause artifacts in RMN due to their magnetic properties. A long scanning time is needed for imaging while low accessibility and high price make this technique presently not readily available for soil-root water studies. Neutron radiography (and tomography) has been recently introduced for imaging roots and water (Nakanishi, 2005; Esser et al., 2010). The technique is based on the attenuation of a thermal neutron beam and is highly sensitive to $\mathrm{H}$ atoms and water. It enables the imaging of roots and water at high spatial resolution $(0.1-0.5 \mathrm{~mm})$ and high precision of the water content $\left(1\right.$ to $\left.5 \times 10^{-3} \mathrm{~m}^{3} \cdot \mathrm{m}^{-3}\right)$. The technique requires however rather thin and small root boxes (rhizotron $\sim 30 \mathrm{~cm}$ ). The production of a neutron beam, together with imaging capabilities, is possible only in a few places around the world and makes it hardly available for routine measurements.

A more accessible approach to study the soil-water-root system is the light transmission imaging technique, described in details in Procedure B. Originally set for studying water infiltration instability in coarse sand porous media (Glass et al., 1989), the design has been adapted to allow plant growth in an adequate sandy substrate in rhizotrons and for getting time and spatial variations of soil water. These 
variations can then be linked to water uptake, in relation with root colonization and root system architecture (Garrigues, 2002; Garrigues et al., 2006). Making use of only rhizotron, camera and a light source, the technique is easily scalable for phenotyping a range of root systems in relation with water uptake properties (Lobet, 2013). Coupled with modeling and complementary data, the technique can give access to plant functions/properties such as the hydraulic properties of the root system, the root growth rate affected by water content...

It shall be noticed that all of the preceding imaging methods are adapted to the scanning of samples in the laboratory. In the field, Electrical resistivity tomography has a high potential for imaging soil water content and water uptake by crops with time (Srayeddin and Doussan, 2009) but presently no method is able to simultaneously image water and the roots in the soil. Root evaluation still mostly relies on destructive sampling for field studies.

\section{Rationale of the technique:}

The technique is based on attenuation of the light passing through a rhizotron, in which roots grow and take water up (Figure 1). The light attenuation is directly linked to the water content. The technique uses easily available materials, software programs and standard CCD cameras for imaging and is cost effective. As the measurement time is short, it enables a high temporal resolution. A high spatial resolution can also be achieved, on the order of $0.2-0.5 \mathrm{~mm}$. The technique pipeline can be designed to allow for multiple rhizotrons scanning and monitoring over time, in order to phenotype a range of genotypes in relation with their water uptake/root soil colonization or root architecture properties (Lobet, 2013). The measurements can be qualitative (i.e., quantifying only differences of water through time or between plants) or quantitative with a calibration step.

However, the light imaging technique has also drawbacks: (i) Plant roots grow in a thin slab of soil and is more a 2D than 3D approach. (ii) As the soil volume is rather low and soil hydric properties are those from a sandy medium, processes related to water uptake in soil (e.g., water drawdown near root, water deficit) are accelerated/amplified compared to a natural 3D soil (depending on the climatic demand). (iii) The soil in the rhizotron is specific (sand + clay) to be translucent and the technique cannot be used with a natural, opaque, soil. (iv) Bulk density of the soil is rather high, about 1.5-1.6 g/cm ${ }^{3}$, lower density results in a repacked soil which is not stable through time. At least for maize, lupine, Arabidopsis the bulk density and soil type did not impede/alter root growth.

To date, most applications with light transmission imaging have been water shortage experiments and analyze the water uptake pattern in relation with root distribution/architecture or root hydraulics (Figure 2). However, this technique can be used to examine water uptake as a function of age/plant stage; to study interaction/competition between plant neighbors; to follow the effects with time of humectation/drying cycles; the interaction between localized irrigation and root growth/water uptake; split-roots or partial root zone drying can also be explored as well as root growth for various heterogeneous water content conditions or induction/regulation of aquaporins. Complementary data, such as leaf water potential, transpiration of leaves, or other physiological measurements can be of interest to examine water relations at the plant level. 


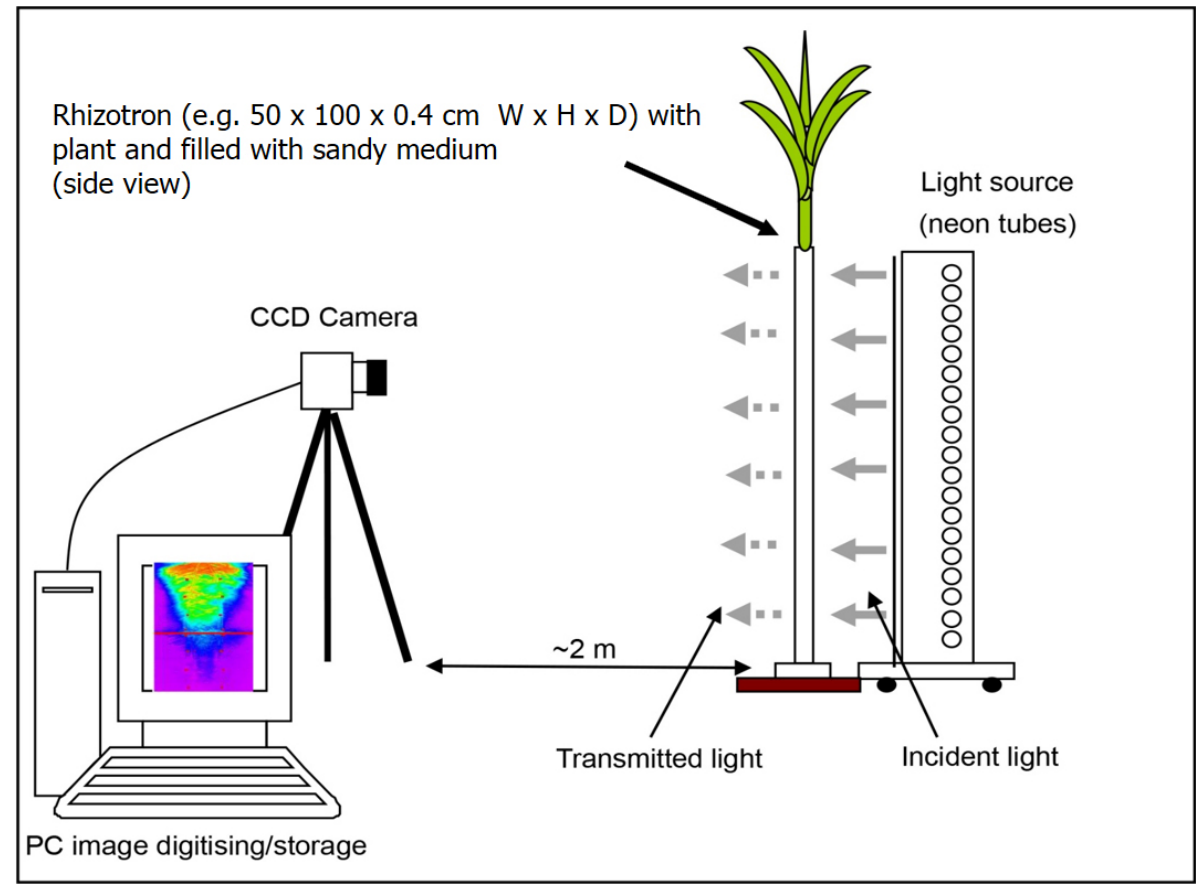

Figure 1. Schematic layout of the experimental system for imaging roots and soil water content (reprint from Garrigues et al., 2006 with permission from Plant and Soil)

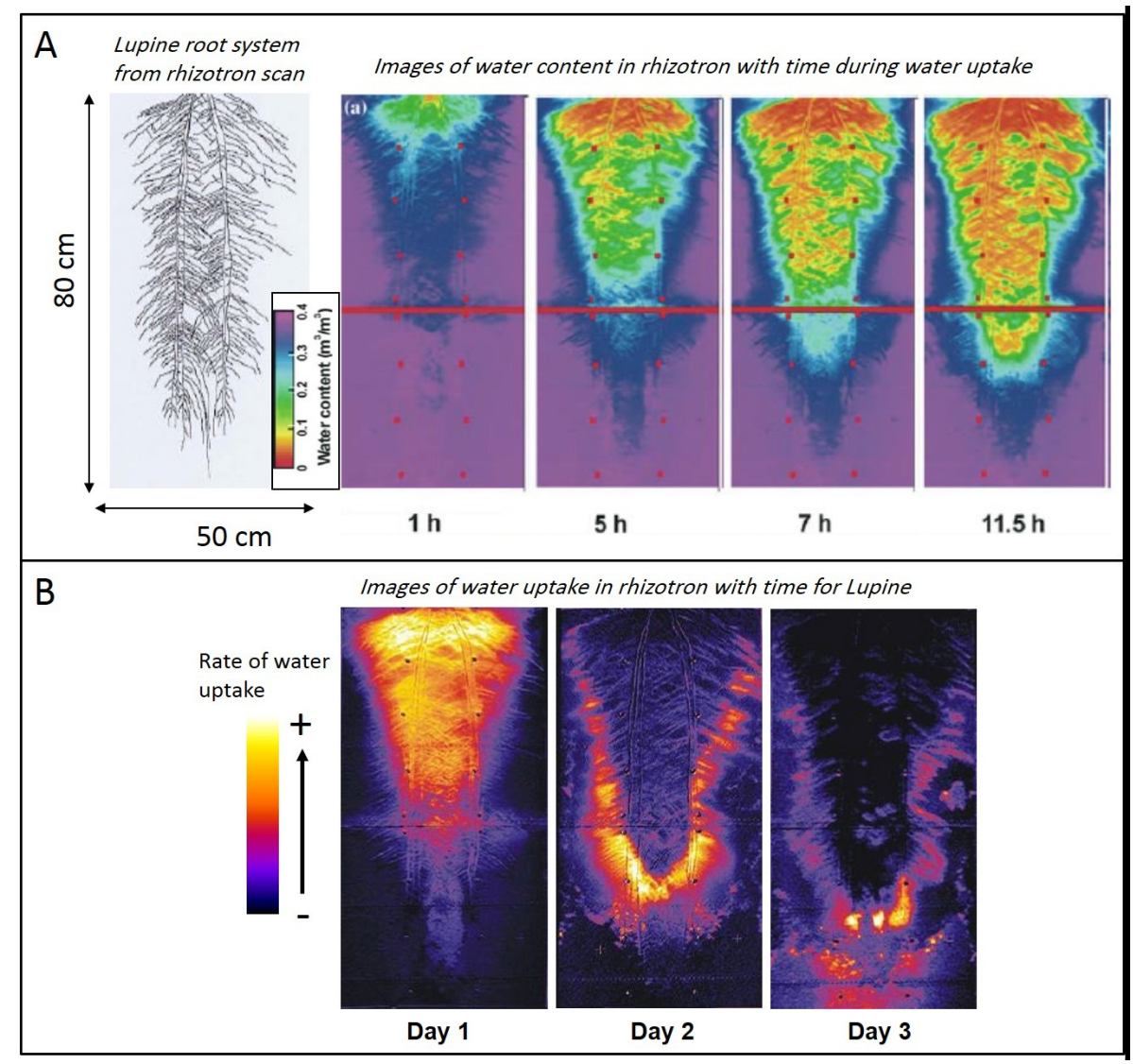

Figure 2. Examples of results from Light transmission imaging of the soil-root system. A. Variation with time (after the end of irrigation) of the water content in the soil of the rhizotron. The 
soil is colonized by a 50-days old Lupine whose root system is shown on the left. B. Water uptake rates of the Lupine in the rhizotron, derived from the difference between images of water content (shown in A) in the morning and evening. A downward and lateral spreading of uptake is visible. This spatial-temporal pattern depends on root architecture, root hydraulic conductance distribution in the root system and soil hydric properties. (Panel A is adapted from Doussan et al. 2006)

\section{Theoretical background:}

The principle of the technique relies on the fact that the light transmitted through a sandy porous medium (sand + air + water) increases with the water content. This variation in transmitted light intensity with water content is linked to the physical processes of reflection/refraction of light. Indeed, the light passing through the different phases of the porous medium is not only exponentially absorbed, but also reflected and refracted at the interfaces between the phases. For the later processes, the transmitted intensity of the passing light is a function of the refractive index of the two phases and angle incidence. The Fresnel's law gives the light transmission ratio $\left(\tau=I_{v} / l_{i}\right.$; with $l_{v}$ : intensity of transmitted light, $l_{i}$ : intensity of the incident light) at the interface of two media for a normal incidence:

$$
\tau=\frac{4 n}{(n+1)^{2}}
$$

where $n$ is the ratio of the refractive indices of the two phases. When using the refractive index of sand, water and air $\left(1.6,1.33,1.0\right.$ respectively), the transmission ratio for the sand-air ( $\left.\tau_{\text {sa }}\right)$ interface is 0.946 while for sand-water interface $\left(\tau_{\mathrm{sw}}\right)$ it reaches 0.991 (Tidwell and Glass, 1994). Hence, when water replaces air at sand interfaces, the transmitted light increases.

Tidewell and Glass (1994) generalized equation (1) to a whole porous medium, assuming that a pore is full or empty of water:

$$
I_{v}=I_{v d} \exp \left[-\left(K_{w}-K_{a}\right) d_{w}\right]\left(\frac{\tau_{s w}}{\tau_{s a}}\right)^{2 . S . k}
$$

where $I_{v d}$ is emergent light intensity of the dry sample, $K_{w}$ and $K_{a}$ are the light absorption coefficient for water and air, respectively; $d_{w}$ is the total thickness of water filled pores, $S$ is the water saturation: $S=\theta / \theta_{S}$ with $\theta$ volumetric water content and $\theta_{s}$ water content at saturation), $k$ is the average number of pores across the sample.

As $K_{w}$ and $K_{a}$ nearly equal, eq. (2) can be approximated by:

$$
I_{v} \approx I_{v d}\left(\frac{\tau_{s w}}{\tau_{s a}}\right)^{2 . S . k}
$$


As the dry state for estimating $I_{v d}$ is not readily attainable after plant growth in the medium and (3) is dependent on the bulk density of the sample, we can make use of the saturated state for normalization between samples. Using the ratio $\frac{\Delta I_{v}}{I_{v s}}$, where $\Delta I_{v}=I_{v s}-I_{v}$, with $I_{v s}$ the emergent light intensity at water saturation, equation (3) can be transformed to:

$$
S=\frac{\theta}{\theta_{s}}=1+\left(\frac{1}{2 k \ln \left(\frac{\tau_{s w}}{\tau_{s a}}\right)}\right) \cdot \ln \left[1-\frac{\Delta I_{v}}{I_{v s}}\right]
$$

Based on (4), fitting a relationship between $S$ and $\ln \left(1-\Delta J_{v} / I_{v s}\right)$ is the rational for calibration and the conversion of images' pixel intensity into water content.

\section{Materials and Reagents}

A. Growing media for plant

1. Filter paper

2. Petri dishes

3. Sand: "Fontainebleau sand" (VWR, catalog number: $27460.364,5 \mathrm{~kg}$ )

4. Clay: hectorite (Elementis specialties: Bentone $\mathrm{MA}^{\circledR}$ )

5. Coarse sand/gravel (2-3 $\mathrm{mm}$ diameter, such aquarium sand)

6. Detergent: TFD4 (Dutscher, catalog number: 711169B)

7. Nutrient solution: modified Hoagland solution (see Recipes, chemicals available from VWR, Fisher Scientific, Sigma-Aldrich, ...) made with:
a. $\mathrm{KNO}_{3}$
b. $\mathrm{Ca}\left(\mathrm{NO}_{3}\right)_{2} \cdot 4 \mathrm{H}_{2} \mathrm{O}$
c. Fe-EDTA
d. $\mathrm{MgSO}_{4} \cdot 7 \mathrm{H}_{2} \mathrm{O}$
e. $\mathrm{NH}_{4} \mathrm{NO}_{3}$
f. $\mathrm{KH}_{2} \mathrm{PO}_{4}$
g. $\mathrm{H}_{3} \mathrm{BO}_{3}$
h. $\mathrm{MnCl}_{2} \cdot 4 \mathrm{H}_{2} \mathrm{O}$
i. $\mathrm{ZnSO}_{4} \cdot 7 \mathrm{H}_{2} \mathrm{O}$
j. $\mathrm{CuSO}_{4}$
k. $\mathrm{H}_{3} \mathrm{MoO}_{4}$ or $\mathrm{Na}_{2} \mathrm{MoO}_{4} \cdot 2 \mathrm{H}_{2} \mathrm{O}$
I. $\mathrm{KOH}$ 
B. Construction of Rhizotrons (height $x$ width from $30 \times 30$ to $100 \times 50 \mathrm{~cm}$ )

1. PMMA (Plexiglas/Perspex) sheets: Transparent and colourless, $5 \mathrm{~mm}$ thick (minimum)

2. PVC rod: $1 \mathrm{~cm}$ high, $4 \mathrm{~mm}$ thick

3. Aluminum flat bars: $4 \mathrm{~mm}$ thick, $1 \mathrm{~cm}$ width (see Notes)

4. Corner shaped aluminum bar, $1 \times 1 \mathrm{~cm}$

5. Stainless steel and nylon bolts (and nuts): $20 \mathrm{~mm}$ long $\times 3 \mathrm{~mm}$ diameter

6. Black matt tape

7. Plastics (PVC, PPMA, Altuglass) (is easily available from local retailers, e.g., Gaches Chimie, abaqueplast: abaqueplast.fr)

8. Aluminum bars (available from local DIY stores)

C. Construction of Light source and colorimetric scale (if needed)

1. Fluorescent tubes (e.g., Philips TLD 18W/840-Cool white color)

2. Wood or other materials for constructing the frame of the light illuminating box

3. Light diffusing sheet of PMMA: 4 mm thick, white colored (Altuglass, catalog number: 100 27018)

\section{Equipment}

1. CCD Camera: 6 to 12 Mpixels, 8 to 14 bit depth for colors, RAW format available, computer driven interface for remotely shooting the picture and transferring the image file, manual adjustment possible

2. Camera lens: 50 to $120 \mathrm{~mm}$ focal length, aperture $\sim \mathrm{f} 2-\mathrm{f} 22$

3. Tripod for camera

4. Balance for weighing rhizotrons ( $20 \mathrm{~kg}$ range for the larger $1 \times 0.5 \mathrm{~m}$ rhizotron)

\section{Software}

1. Image processing Software: Fiji (Schindelin et al., 2012, open-source software based on ImageJ, https://imagej.net/Fiii)

2. For processing imaged root systems: SmartRoot (Lobet et al., 2011, Open-source, based on ImageJ, https://smartroot.github.io/) or for simple segmentation of root system (and length, diameter of roots): IJ_Rhizo (Pierret et al., 2013, Open-source, based on ImageJ, http://www.plant-image-analysis.org/software/lJ Rhizo)

\section{Procedure}

Note: Depending on the material, equipment already available, not all of the steps below need to be completed. In particular, the first step (construction of equipment) can be skipped if already available or alternatives are available in the laboratory. 
A. Construction of the equipment (rhizotrons, light source and water content calibration cells)

1. Building of the rhizotrons:

The rhizotron is a transparent box in which the soil is filled and the plant is grown. The faces of rhizotron are made of 2 transparent PMMA (Plexiglas) sheets. Height and width can be adapted to the root system of the plant studied. We used $100 \times 50 \mathrm{~cm}$ for blue lupine and maize, $30 \times 30$ $\mathrm{cm}$ for Arabidopsis. The thickness of plexiglass sheet is $5 \mathrm{~mm}$ to be sufficiently rigid. As an example of rhizotron design (Figure 3):

a. The 2 Plexiglas faces are separated on left and right by rigid aluminum bars (width $=1 \mathrm{~cm}$, thickness $=4 \mathrm{~mm}$, see Notes, length = length of Plexiglas face). A corner shaped aluminum bar on each side increases the rigidity of the assembly (Figure 3 ).

b. Some silicone grease is applied along the aluminum bars to make them watertight.

c. For the bottom, a rectangular plastic (PVC) rod is used: $\sim 1 \mathrm{~cm}$ high, thickness $=4 \mathrm{~mm}$, width = width of plexiglass $-2 \mathrm{~cm}(2 \mathrm{~cm}$ is the sum of the widths of the 2 aluminum bars $)$ and perforated with $3 \mathrm{~mm}$ holes for drainage.

d. Use $20 \mathrm{~mm}$ long $\times 3 \mathrm{~mm}$ diameter bolts (and nuts) made from stainless steel and nylon ( 20 stainless and 16 nylon for $100 \times 50 \mathrm{~cm}$ rhizotron) to assemble the rhizotron.

e. For each nylon bolt, a spacer is made by cutting a small PVC pipe (length $=4 \mathrm{~mm}$, external diameter $=7 \mathrm{~mm}$, internal diameter $=4.5 \mathrm{~mm}$ ). These internal spacers are needed to inhibit lateral movement of Plexiglas sheets with time (particularly for large ones). We used a spacing of about $12 \times 12 \mathrm{~cm}$, vertical and horizontal directions, for internal spacers along the PMMA sheet for $100 \times 50 \mathrm{~cm}$ rhizotron.

f. Aeration holes $(2 \mathrm{~mm})$ are drilled into one face of the Plexiglas sheet.

g. Black, matt, tape is put along the edges of the rhizotron

Figure 3 shows assembling of rhizotron. The top of rhizotron can be enlarged by drilling in the 2 Plexiglas to accommodate positioning of large seeds. An alternative design of rhizotrons can be found at files.figshare.com/224189/rhizotron blueprints.pdf, from Lobet and Draye (UCL). 

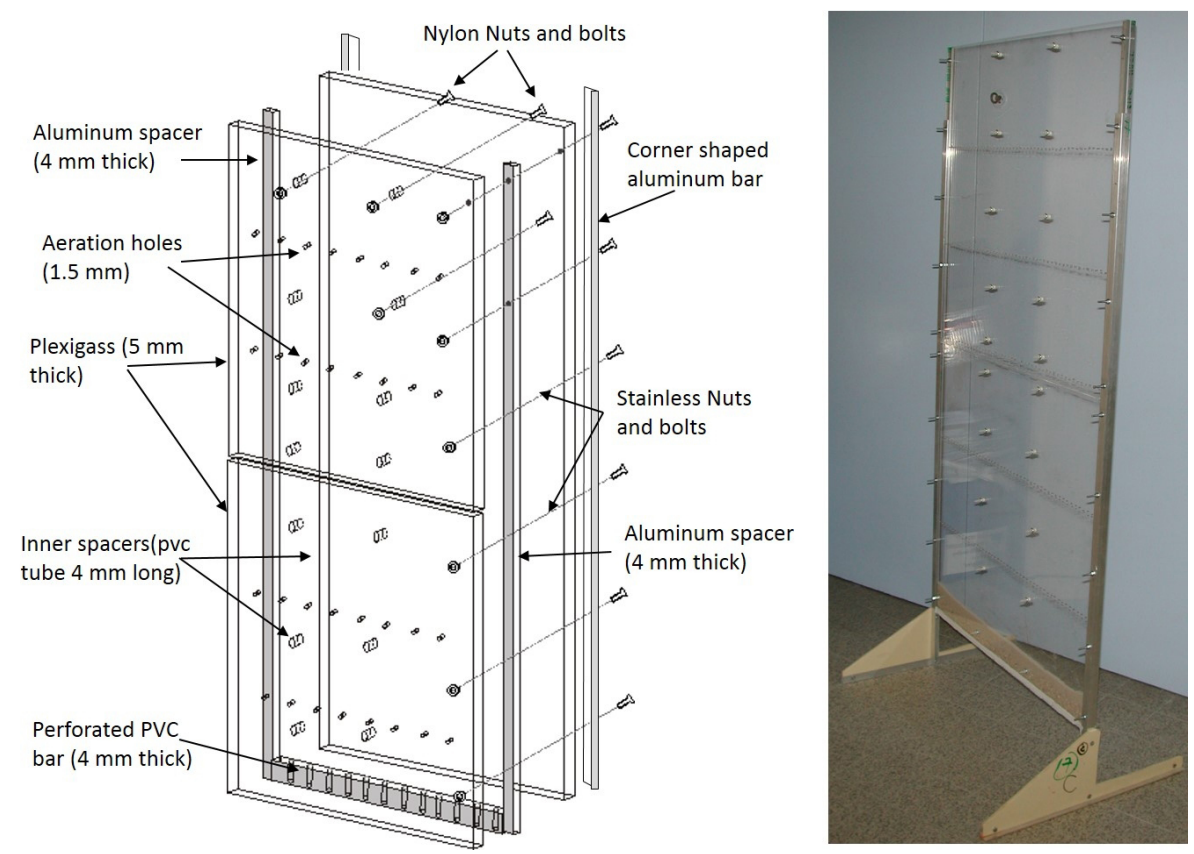

Figure 3. Rhizotron. Schematic assembling of a $100 \times 50 \mathrm{~cm}$ transparent rhizotron (Left) and a picture of the assembled rhizotron (Right), with the installed coarse sand and gravel draining layer at the bottom.

2. Constructing the light source (if not already done/available):

A light source is needed to produce the light that will cross through the rhizotron and will be registered by the camera. The light box is made from a frame whose size accommodates the size of rhizotrons (Figure 4). We found it convenient to use wood to construct the frame. For example, for a large rhizotron $100 \times 50 \mathrm{~cm}$, the wood frame is $130 \times 80 \mathrm{~cm}$.

a. Within the wood frame, the light is emitted by fluorescent tubes. For a large rhizotron, 19 fluorescent tubes, $56 \mathrm{~cm}$ length, $18 \mathrm{~W}$ (Philips TLD 18W/840-Cool white color) are aligned along $116 \mathrm{~cm}$ height. For smaller rhizotrons, e.g., $30 \times 30 \mathrm{~cm}, 4$ fluorescent tubes are sufficient for illuminating a $45 \times 40 \mathrm{~cm}$ surface area.

b. The inner walls of the wood box shall be white to increase the light efficiency.

c. For aeration and limiting heat, holes ( $\sim 5-7 \mathrm{~mm}$ diameter) are drilled on the top, left and right side, of the wood box.

d. Affix on the side of the light box facing the rhizotron a white, light diffusing, sheet of PMMA (4 mm thick), to homogenize the light from fluorescent tubes. It can be fixed with screws on the wood box.

3. Setting a colorimetric scale

Variations with time of the intensity of the light emitted by the light box or captured by the camera (because of variation in exposure time or thermal noise for example) might happen. To get rid of these variations not linked with water content in the rhizotron, a light transmission grey scale, acting as a reference for image adjustment, is needed. The grey scale also accounts for possible nonlinearity of $C C D$ or camera built in process over the light intensity range recorded. The scale 
can be constructed from more or less transparent PMMA materials. We found a better way to construct it by using 8 known grey values printed on normal paper by imaging software (ImageJ, paint...). The grey levels are: 10, 25, 50, 100, 150, 205, 233, 255, as coded for an 8 bit-grey scale image. The zero level (black) is taken from a black side of the light box. Each paper printed grey-values is sandwiched between 2 white diffusing PMMA light diffusing sheets, as above. PMMA and paper hold together with matt black adhesive tape. This results in rectangular blocks which are placed on a side of the light box with adhesive tape, setting a light transmission grey scale (Figure 4).
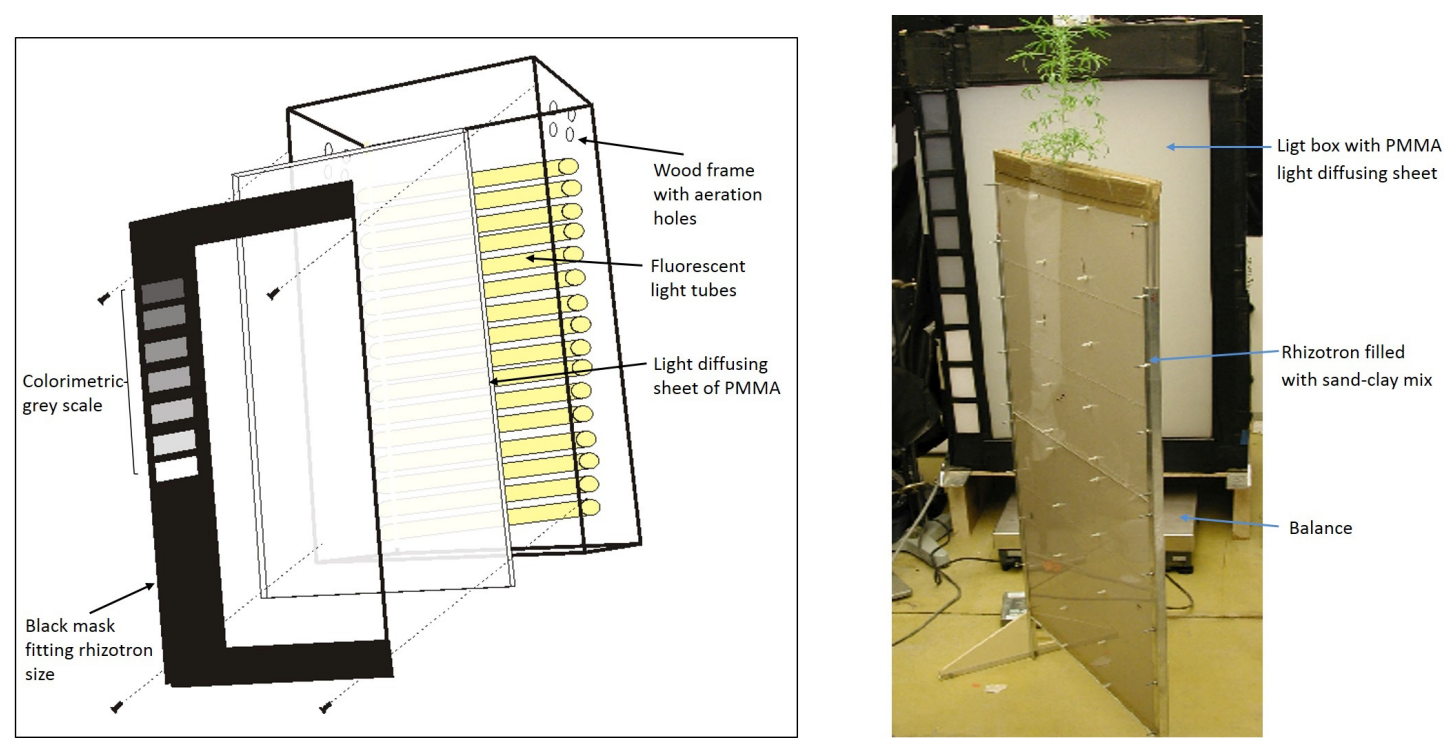

Figure 4. Light box. Schematic assembling of the light box for back illuminating rhiztrons (Left) and a picture of the assembled light box, with colorimetric grey scale and a filled rhizotron, with narrow leaf lupine. During experiment the rhizotron was installed on the balance in front of the light box (right).

4. Adjusting the light source to rhizotrons

The light box shall be greater than rhizotrons, incorporating the colorimetric scale for getting homogenous light trough samples. It is necessary to create a mask of the size of the rhizotron fixed over the white diffusing PMMA sheet of the light box. The mask needs to be also adapted to the colorimetric scale, next to the rhizotron (Figure 4). This mask can be made from cardboard or be a wooden frame painted black. A black foam ribbon between the mask and the rhizotron will occult light there. If the rhizotron does not stay on front of the light box during the experiment, being removed after each picture, the rigid wooden frame can be adapted to serve also as rhizotron holder. It is indeed important that the rhizotron stays at the same place for each imaging experiment to get the best spatial precision in the images and in the geometric registration. A slide on the wood frame with wing bolts that press the rhizotron against the frame and foam ribbon will hold the rhizotron at the same position for successive imaging sequences. 
5. Construction of water content calibration cells

A calibration cell enables to fit equation (4) in the form

$$
S=\frac{\theta}{\theta_{s}}=a+b \ln \left[1-\frac{\Delta I_{v}}{I_{v s}}\right]=a+b \ln \left[\frac{I_{v}}{I_{v s}}\right]
$$

where $a$ and $b$ are to be fitted.

The calibration cell is made from the same materials as rhizotrons. Aluminum bars ( $4 \mathrm{~mm}$ thick, $1 \mathrm{~cm}$ wide, $14 \mathrm{~cm}$ length) are glued on to a transparent PMMA sheet (50 cm length, $14 \mathrm{~cm}$ high, $5 \mathrm{~mm}$ thickness) to delimit 7 compartments, 6 -cm width (Figure 5). These compartments will be filled with the sandy soil prepared in Step B1 at 0, 2, 5, 7, 10, 15, 20\% gravimetric water content ( $g$ water/g dry soil). The water used is tap water. The front face of the calibration cell is another, removable, PMMA transparent sheet and holds in place with screws or clips. Black, matt, adhesive tape is put along the edges of the cell when finished and filled. Crosses (4) drawn on PMMA with a fine permanent marker serve as a spatial reference for image geometric registration.

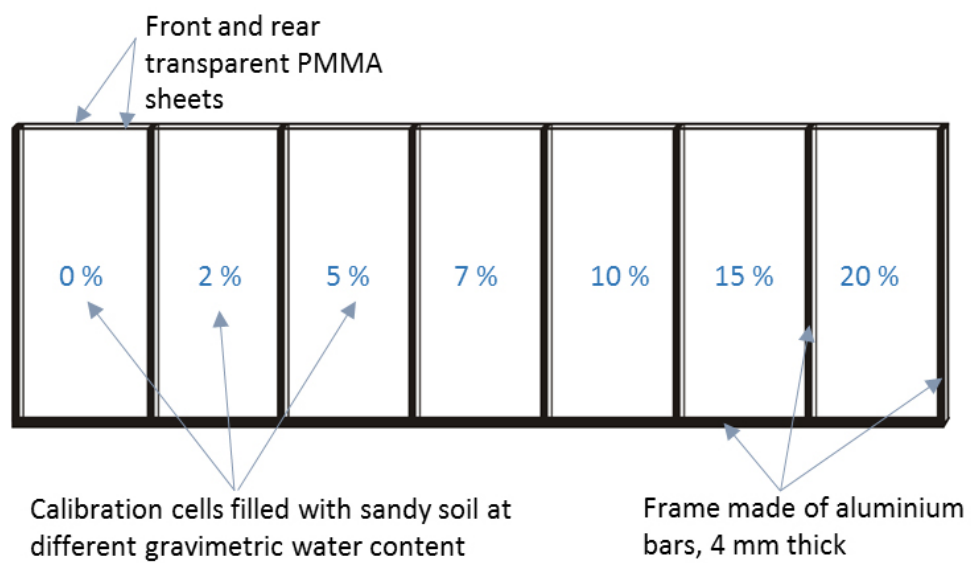

Figure 5. Scheme of the water content calibration cell. A frame of flat aluminum bars, $4 \mathrm{~mm}$ thick, is sandwiched between 2 transparent PMMA sheets. The aluminum frame delimitates cells which are filled with sandy soil of known gravimetric water content.

B. Experimental procedure

1. Preparation the soil growing medium

The soil used for growing plants in rhizotrons is a sand-clay mix. The sand is "Fontainebleau sand", a clear, pure, silica sand with a mean diameter of about $200 \mu \mathrm{m}$. The clay is the hectorite (swelling) clay, which is transparent when mixed with water. Sand hydraulic properties may depend on how the sand is clean at the beginning of the experiment (because of dust, grease residues...). It is recommended to wash the sand to obtain a reproducible initial state. The procedure is: 
a. Put the sand in a 0.5\% dilute solution of TFD4 detergent and boil for 30-40 min.

b. Rinse the sand under hot tap water for $15 \mathrm{~min}$, and then boil for another $15 \mathrm{~min}$.

c. Rinse the sand with tap water first and demineralized water afterward.

d. Dry the sand in an oven at $60{ }^{\circ} \mathrm{C}$ for $24 \mathrm{~h}$.

e. Prepare the sand and clay mix: Mix $98.5 \%$ of dried sand and $1.5 \%$ clay (by weight).

f. To stabilize the sand-clay association, the mixture is saturated with tap water and oven-dry at $105^{\circ} \mathrm{C}$.

g. After mixing and drying, this sand-clay mix is stored in closed containers.

Hydric properties that we have determined of this sandy-clay soil are shown Figure 6 (see Garrigues, 2002 for more details) and can be used for converting water content to matric potential and for soil-root water modeling purposes.
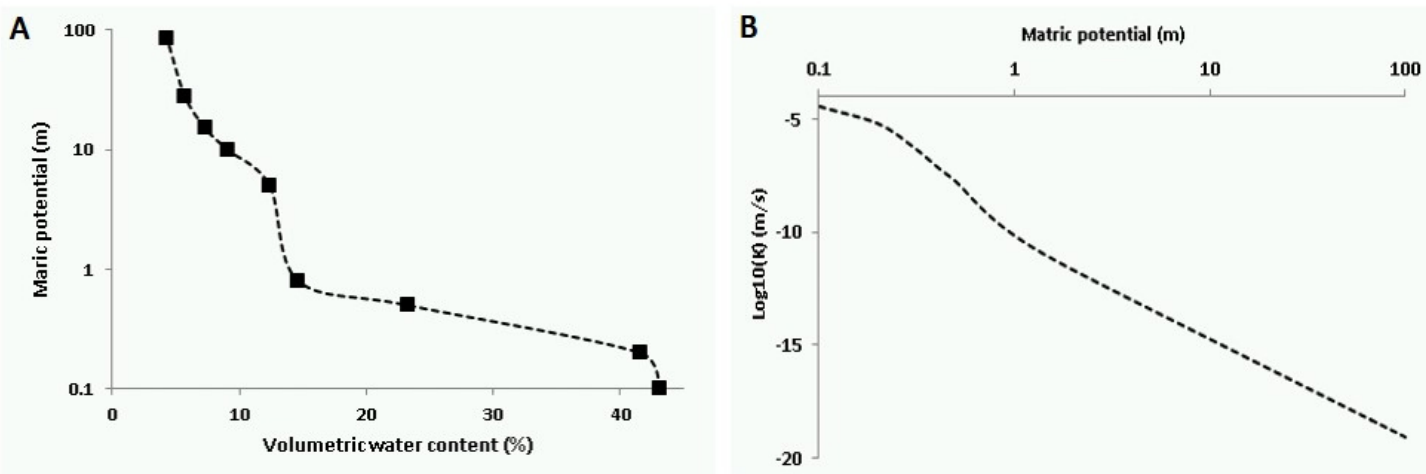

Figure 6. Retention curve (A) and hydraulic conductivity, expressed in a logarithmic scale

(B) of the sand clay mix (98.5\% sand-1.5\% hectorite clay). The soil matric potential is expressed in hydraulic head units (meters).

2. Rhizotron filling and plant culture

a. The filling of rhizotron with the sand-clay mix is an important step in obtaining reproducible results. A layer of coarse sand (2-3 $\mathrm{mm}$ diameter), acting as a draining layer and preventing fine sand to leak out, is first poured into the rhizotron to achieve a height of about $2 \mathrm{~cm}$. This height is recorded ( $\left.h_{\text {coarse}}\right)$. The rhizotron is then weighted: this "empty" weight is recorded $(\mathrm{Me})$.

A mass of sandy soil is prepared. This mass can be estimated from $1.7^{\star} \mathrm{V}_{\text {rhizo, }}$, where 1.7 $\mathrm{g} / \mathrm{cm}^{3}$ is an upper bound of the bulk density of the final sand packing and $V_{\text {rhizo }}$ is the inner volume of the rhizotron, estimated from width, length and thickness dimensions.

The mass (in excess) of sand is put into the rhizotron once. This can be achieved with a homemade funnel (with trapezoidal shape), which aperture and length fit the rhizotron. The funnel is adapted and fixed to the top of rhizotron mouth. The sand is poured and accumulated into the funnel at about the same height along the rhizotron, while a paper sheet closes the funnel's aperture. Removing the sheet causes a regular fall of the sand. During the fall, sand is redistributed by collisions with the inner spacers enhancing 
homogeneity of the packing.

Always with the funnel containing the remaining sand on the rhizotron, the sand is compacted by tapping along the 2 aluminum edge spacers with a small plastic hammer. The number of strokes shall be the same between each rhizotron made ( 15-20). The weight of the dry, filled, rhizotron is recorded $\left(M_{d f}\right)$ and the dry bulk density $\left(\rho_{d}\right)$ as well as an approximation of porosity $\left(\theta_{\mathrm{s}}\right)$ are given by:

$$
\rho_{d}=\left(M_{d f}-M_{e}\right) /\left(V_{\text {rhizo }}-V_{\text {coarse }}\right) \text { and } \theta_{s}=1-\left(\rho_{d} / \rho_{s}\right)
$$

where $V_{\text {coarse }}$ is the volume of coarse sand in the rhizotron $\left(=h_{\text {coarse }} x\right.$ Widthrhizo $x$ Thickness rhizo) and $\rho_{\mathrm{s}}=2.65 \mathrm{~g} / \mathrm{cm}^{3}$ is the solid density of sand grains.

The rhizotron is labeled and in order to get spatial references in images of the rhizotron for geometrical registration, crosses are drawn with a fine permanent marker at the corners of the rhizotron.

b. The rhizotrons are water saturated by placing them vertically in a container large enough to accommodate them and rising slowly the water level in the container. Before saturating the rhizotron, aeration holes in the Plexiglas need to be covered by adhesive tape to avoid the sand to escape. The weight after saturation can be recorded to get a first measure of the saturated water content.

Note: At dry state and once saturated, rhizotrons shall be handled precautiously in order to not change soil compaction. After drainage occurred, the sand inside the rhizotron will be more stable.

c. Large seeds (e.g., maize) are pre-germinated on moist filter paper in Petri dishes and transplanted in rhizotron when radicle is about $1 \mathrm{~cm}$ long. A potting mix is added and moistened on top and side of the seed to maintain a favorable medium for seed development. Smaller seeds (e.g., Arabidopsis) are put directly on a moist potting mix layer (about 3-4 mm high).

d. To limit evaporation from top soil in rhizotron, a layer of coarse sand (or expanded clay) is added at the top of the rhizotron (the mass added is recorded). Rhizotron are covered on top and sides with opaque plastic sheets to protect them from light (root growth, algal growth) and evaporation.

e. During plant growth in a growth chamber, rhizotrons are irrigated with a nutrient solution adapted to the plant. Frequent irrigation is necessary in order to not water stress the plant in the thin sandy medium. The irrigation can be done by automated drip irrigation to maintain the soil at field capacity (for example $\sim 10-15 \mathrm{ml}$ each $4 \mathrm{~h}$ during the day period). When plants are developed, transpiration may reach 1-10 $\mathrm{g} / \mathrm{h}$ depending on the plant, its age and potential evapotranspiration. During this cropping phase, water lost by transpiration needs to be replaced by irrigation. Evaluation of transpiration can be done by weighing the rhizotrons regularly. 
Note: A modified Hoagland is often used (see Recipes-Table 1).

f. The rhizotrons can be installed vertically, but if one wants to follow root growth, rhizotrons can be tilted approx. $30-35^{\circ}$ to get roots growing along a PMMA face. Roots can be followed through time by manually tracing with permanent markers on a transparency film fixed on the rhizotron face, or by taking a picture with a further process of root segmentation, if contrast/resolution are good enough.

g. At the end of the whole experiment, the rhizotron is laid horizontally, a PMMA face removed and roots can be exposed (possibly using a brush) for root recording (manually with a transparency film or by taking a picture).

3. Imaging of rhizotrons

\section{Timing of an imaging experiment:}

For a water shortage experiment or following a rewetting, the rhizotrons are imaged regularly. For a drying experiment, an imaging frequency of $2 \mathrm{~h}$ is enough. Depending on the plant type, age and climatic conditions in the growth chamber, the water shortage experiment may last from 3 days (e.g., maize, lupine) to 8-10 days (e.g., Arabidopsis) before water in the rhizotron is nearly completely depleted.

\section{Warmup, location of light box and camera:}

Light emission of fluorescent tubes of the light box will increase after switching on and a warmup of about 10 min of the lamps is recommended before the first image is recorded. The light box and camera can be placed ideally in the growth chamber where the rhizotron stays, minimizing transport, or in a dedicated room. In either case, to avoid undesirable light reflection on the walls, black sheets/tarps are put on side walls between rhizotron and camera. A specific casing can also be made protecting from outside light, black inside, with a rectangular or truncated pyramidal shape enclosing the camera and arriving at the light box. To avoid at most geometric errors, the camera and rhizotrons (cf. Step A4) shall stay at the same place between images, and the camera needs to be fixed and not moving. Typical distances between rhizotron and camera are from $60 \mathrm{~cm}$ to $2 \mathrm{~m}$, depending on the size of rhizotron and camera lens used.

\section{Camera adjustments:}

In a typical water shortage experiment, the first image of the time sequence would be the reference image at (near) saturation of the series. This can be done by increasing irrigation a few hours before starting the experiment. The water saturated image is the brightest image in the experiment, and the camera parameters are set at this step (aperture and possibly shutter speed) for the whole experiment in order to get a bright but not saturating image (i.e., pixels values lower than 255 for 8 -bit image). This can be verified with Fiji/Image J software (Schindelin et al., 2012) with the threshold function. Typical settings are aperture $f / 4$ to $f / 8$, shutter speed 1/125 to $1 / 20$ second. In order to minimize noise and light variation effects, at each measurement time, 3-4 images are taken successively which will be averaged later. 
Note: Full saturation can also be done at the end or beginning of the experiment by rising water level slowly in a container with the rhizotron. Care should be taken to close lateral aeration holes (with tape).

\section{Weighing of rhizotron:}

Just before each image acquisition, the rhizotron is weighed to estimate the transpiration and mean soil water content.

4. Establishing a water content calibration with the water content calibration cells

a. Sandy soil samples are prepared at different values of gravimetric water content $(0,2,5,7$, $10,15,20 \%)$. To this end, a dry mass of soil $\left(M_{s}\right)$ is prepared in excess to fill each cell (cf. Step A5; about $80 \mathrm{~g}$ for each cell described in Step A5). A mass of water $\left(M_{w}\right)$ is prepared to get the desired gravimetric water content percentage $W: M_{w}=M_{s} \times W / 100$. The dry soil is distributed over a dish in a thin layer and the amount of water is spread over the soil with a spray. The soil and water are thoroughly mixed, transferred into a plastic or glass container, which is sealed and stored in a cool place for $48 \mathrm{~h}$ (to get moisture equilibrium).

b. With the front side of the calibration cell removed, a mass of moist soil $\left(M_{m}\right)$ is weighed to reach a bulk density of $1.65 \mathrm{~g} / \mathrm{cm}^{3}$ in each cell. This mass can be calculated with:

$$
M_{m}=\rho_{d} V\left(1+\left(\frac{W}{100}\right)\right)
$$

where, $\rho_{d}=1.65 \mathrm{~g} / \mathrm{cm}^{3}$, and $V$ is the volume of the cell to be filled.

The soil is deposited along the cell, pressed and leveled (using the aluminum bars) to fill the entire cell. This is repeated for each calibration cell. Cares need to be taken to not leave sand on aluminum bars.

Note: It is useful to train before making the final calibrated cells in order to obtain as most homogenous filling as possible. Another option is to fill cell from the top and to compact from the top each $3 \mathrm{~cm}$. However, this results in heterogeneous layered medium but, from images, the mean pixel intensity over the cell is representative of the mean water content.

c. Unused sand in excess is collected to determine the actual gravimetric water content. To this end, the moist soil sample is weighed, then dried for $24 \mathrm{~h}$ at $105^{\circ} \mathrm{C}$ and reweighed. The gravimetric water content is the ratio of water mass (the difference between moist and dry soil) to the dry soil mass.

d. Silicon grease is added along aluminum bars and the calibration box closed with black tape around the edges of the box. A picture of the calibration cell with the light box is taken in the same conditions as rhizotrons (cf. Step B3).

e. As for rhizotron and image processing, the calibration cell is brought to saturation. This is done by adding water slowly with a micropipette in each cell. The range of mass of water $(M w)$ to be added can be estimated with: 


$$
M_{w}=\left(0.38-1.65\left(\frac{W}{100}\right)\right) \times V
$$

where, 0.38 is the theoretical volumetric water content at saturation for a medium having a bulk dry density of $1.65 \mathrm{~g} / \mathrm{cm}^{3}$. The saturated calibration cell is let to equilibrate for a few hours and then a picture of the saturated calibration cell with the light box is taken again.

f. The calibration is opened and the sand of each cell is completely sampled. Weigh these moist soils, and then dry in an oven for $24 \mathrm{~h}$ at $105^{\circ} \mathrm{C}$ and reweigh. The gravimetric water content approximating saturation can then be calculated as well as the dry bulk density of each cell, if the volume of the cell is determined.

\section{Data analysis}

1. Processing of the images of rhizotron for water content

Once acquired in the light transmission experiment, the images are processed:

a. If needed: conversion of raw images to uncompressed tiff file (software supplied with camera).

b. Averaging image replicates: using Fiji (using stacks: File $\rightarrow$ Import $\rightarrow$ image sequence; and then Image $\rightarrow$ Stacks $\rightarrow$ ZProject $\rightarrow$ Average Intensity-A macro can be recorded) or with homemade software.

c. Conversion of RGB images to grey levels, with Fiji (Image $\rightarrow$ Type $\rightarrow 8$ or 16 bits, depending on color depth of image) or using Netpbm (Linux software).

d. Geometrical registration of the images of the time series. The first image of the time series acts as a reference. With Fiji the StackReg plugin can be used (Plugins $\rightarrow$ Registration $\rightarrow$ StackReg) or other registration capable program (e.g., homemade program makes use of marks in the image: written crosses and screws for example, with polynomial rectification and resampling with interpolation). The true size of pixel can be calculated from a known length in the image (it will be the same for each image) and camera ( $x, y)$ number of pixels.

e. Adjusting images according to a grey scale reference. Images of the time series can be referenced either to the grey values of the colorimetric scale (from 0 to 255 see Step A3 in Procedure) or to the intensity value of the grey colorimetric scale of the first, water saturated, image. Sampling the intensity of grey values of the colorimetric scale in each image can be done in Fiji by defining masks on each of the colorimetric cells with the rectangular selection tool (cf. http://imagej.nih.gov/ij/docs/guide/146-29.html to create binary masks). These masks are used along with the ROI manager (Analyze $\rightarrow$ Tools $\rightarrow$ ROI manager) where masks can be applied to each image and measured (i.e., getting the mean pixel value, standard deviation in the region of the mask). For each image, the correspondence between the mean pixel intensity of the greys of the studied image and the reference value (i.e., the 0 to 255 eight colorimetric values defined in Step A3 or intensities of the colorimetric cells 
of the water saturated image) can be established using the calibrate function (Analyze $\rightarrow$ Calibrate) or the LUT editor plugin in Fiji. Alternatively, homemade programs which make average of the defined colorimetric zones and adjust the studied image with a cubic spline to the reference colorimetric scale are available.

f. Calculating the water content of pixels in images with the fitted calibration equation (5): $S=$ $\frac{\theta}{\theta_{s}}=a+b \ln \left[\frac{I_{v}}{I_{v s}}\right]$ (cf. below "2. Processing of calibration cell" for fitting). This calculation can be done with Fiji using the image calculator and Math functions (Process $\rightarrow$ Image Calculator, or Math) and selecting 32 bit images type (float values for water content) for the result. For each image of the time series:

i. Calculate the saturation ratio of images: $I_{v} / I_{v s}$, where $I_{v}$ is grey levels of pixels of the image of rhizotron at a given time and $I_{v s}$ those of the image of the rhizotron at saturation (with Image Calculator in Fiji, using the Divide function).

ii. Calculate image of water saturation $S=a+b \ln \left[\frac{I_{v}}{I_{v S}}\right]$ with Log, Multiply, Add functions of Math in Fiji (or alternatively use the macro function of Math to code the equation directly).

iii. Calculate water content image $(\theta)$ from saturation with $\theta=S \times \theta_{S}$ with $\theta_{S}$ the mean value of water content at saturation of the rhizotron determined from weight measurements (see Steps B2 and B3)

iv. The rhizotron part of the result image is cropped and saved in tiff (and text file if needed), for further calculation/processing. Again, homemade programs can do that calculation part.

g. Post-processing of the water content image series includes the calculation over the rhizotron of the mean water content, which will be compared to estimated water content from weight measurements. Specific treatment related to water variations includes conversion of water content into water potential, calculation of images water uptake rate with time (time image differences), estimation of the maximum depth/width of uptake, 1D mean profiles (and standard deviation) of water content, water uptake along the rhizotron. If images of the root system are co-registered with water content images, then processes at the soil-root interface (for water) can be examined, such as local or mean drawdown with distance to root, root type or age. The relationship between root density and uptake or between root growth and water content or potential can also be obtained.

2. Processing of the calibration cell

The calibration cell enables to fit $\mathrm{a}, \mathrm{b}$ in equation (5): $S=\frac{\theta}{\theta_{s}}=a+b \ln \left[1-\frac{\Delta I_{v}}{I_{v s}}\right]=a+b \ln \left[\frac{I_{v}}{I_{v s}}\right]$. The images of the calibration cell are processed as for the rhizotrons (cf. above step 1), except that the value of $\ln \left[\frac{I_{v}}{I_{v s}}\right]$ are estimated from mean values over the same region of interest in each calibration cells for initial and saturated images. The $(a, b)$ coefficients of the calibration function in eq. 5 are estimated from linear regression between water saturation and $\ln \left[\frac{I_{v}}{I_{v s}}\right]$ 
(Figure 7). As the regression changes at low water contents, a second set of parameters is needed in the low saturation range (lower than about $3 \%$ volumetric water content, Figure 7).

The colorimetric scale adjustment of the calibration cell is referenced to the first image of the time series of each rhizotron, resulting in a slightly different calibration equation for each rhizotron.

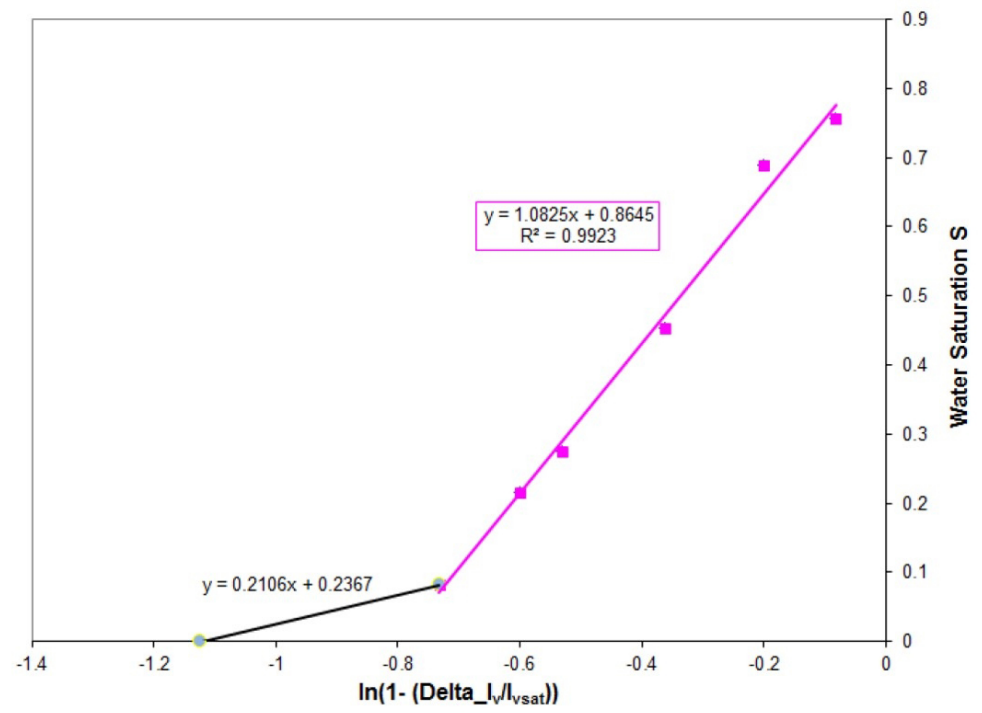

Figure 7. Calibration derived from images of calibration cells between water saturation $\mathbf{S}=\theta / \theta_{S}$ and $\ln \left[\mathbf{1}-\frac{\Delta I_{v}}{I_{v s}}\right]$. The equation of calibration is $S=a+b \ln \left[1-\frac{\Delta I_{v}}{I_{v S}}\right]$ (see eq.5) where $a$ and $b$ are fitted by linear regression. Two regressions are needed.

3. Validation of estimated water content of rhizotron from image processing

To get rid of possible residual effects of variations in compaction between calibration cell and rhizotrons a final test consists in comparing mean volumetric water of rhizotrons estimated from calibrated images and from weighing of rhizotron trough time. This normally results in a regression line with $R^{2}>0.99$, but if the slope is nearly equal to 1 , a small bias (about $1 \%$ in volumetric water content) may appear. In that case, the water content estimated from images can be converted to "true" water content (from weight measurements) by this regression equation.

4. Processing images of root systems

If the root system was traced on a transparency film on front of the rhizotron, the film can be scanned and the resulting image segmented with IJ_Rhizo software (Pierret et al., 2013) for example. A way for vectorizing complex root systems when the rhizotron is disassembled and root system exposed can be found in Lobet and Draye (2013). If following root growth either from transparency film drawings or images of rhizotron trough time is of interest, the SmartToot software (Lobet et al., 2011) would be usefully used as it enables semi-automated tracing of 
roots on an image series. Outputs such as growth, topology, lateral density, diameters can be obtained.

Whatever the root processing software, if the root system in rhizotron is segmented from an image at the same time as the imaging experiment for water content, coregistration of the images of the segmented root system and of the water content in the rhizotron enables to relate root parameters (root density, root age, root types, growth...) and water content or uptake in soil.

5. Going a step further: Use of imaging experiment in modeling

Light transmission imaging of plant water uptake has been designed initially to verify the consistency of detailed modeling of root water uptake. This modeling couples root system architecture, regulation of water flow into and along the root system, mechanistic water transfer in the soil (Doussan et al., 1998; Doussan et al., 2006). This modeling approach has been extended since (Javaux et al., 2008; Schneider et al., 2010). The modeling of light transmission imaging, in the case of more or less tap rooted Lupine root systems, showed that uptake is driven by local soil-root interactions at the single root scale, linked to variation in soil hydraulic conductivity near the root and root radial conductivity. These interactions are modulated at the root system scale by the water distribution and the root axial conductance (Doussan et al., 2006). Variations in root system architecture and distribution of root hydraulic conductance, defining different root systems phenotypes, will give rise to variations in water uptake pattern. Testing these various phenotypes with detailed water uptake models in combination with imaging results of water content, can give access to estimations of hardly measurable parameters such as root hydraulic conductivity, distributed root water uptake rates or root xylem water potential. Combination of modeling and experiment may also help in testing biological and physiological assumptions, such as ABA production and regulation of water fluxes (Lobet, 2013). With the modeling, supported by imaging experiments, plant behavior (e.g., for different root phenotypes) can be extrapolated to other soil/climate conditions (e.g., for looking at the water uptake efficiency), guiding experimental verifications (in the field or controlled conditions) in a later step.

\section{$\underline{\text { Notes }}$}

The $4 \mathrm{~mm}$ void, filled with soil, thickness is a good compromise to get enough light through the rhizotron and enables a good contrast between dry/wet states of the sandy soil used. Slightly larger thickness can be used to accommodate thicker roots (up to $6 \mathrm{~mm}$ ) but at the expense of lower contrast.

\section{Recipes}

1. Modified Hoagland solution (Table 1) 
Table 1. Composition of modified Hoagland solution. The Iron content is doubled in this solution (adapted from Lobet and Draye, 2013)

\begin{tabular}{llll}
\hline Component & & Stock solution & $\mathrm{ml} / \mathrm{L}$ \\
\hline $2 \mathrm{M} \mathrm{KNO}_{3}$ & & $202 \mathrm{~g} / \mathrm{L}$ & 25 \\
$2 \mathrm{M} \mathrm{Ca}\left(\mathrm{NO}_{3}\right)_{2} \cdot 4 \mathrm{H}_{2} \mathrm{O}$ & & $236 \mathrm{~g} / 0.5 \mathrm{~L}$ & 25 \\
$\mathrm{Fe}-\mathrm{EDTA}$ & & $15 \mathrm{~g} / \mathrm{L}$ & $1.5 \times 2=3$ \\
$2 \mathrm{M} \mathrm{MgSO}_{4} \cdot 7 \mathrm{H}_{2} \mathrm{O}$ & & $493 \mathrm{~g} / \mathrm{L}$ & 1 \\
$1 \mathrm{M} \mathrm{NH}_{4} \mathrm{NO}_{3}$ & & $80 \mathrm{~g} / \mathrm{L}$ & 1 \\
$1 \mathrm{M} \mathrm{KH}_{2} \mathrm{PO}_{4}$ & & $136 \mathrm{~g} / \mathrm{L}$ & 0.5 \\
Minors: & & & 1 \\
& & $2.86 \mathrm{~g} / \mathrm{L}$ & \\
& $\mathrm{H}_{3} \mathrm{BO}_{3}$ & $1.81 \mathrm{~g} / \mathrm{L}$ & \\
& $\mathrm{MnCl}_{2} \cdot 4 \mathrm{H}_{2} \mathrm{O}$ & $0.22 \mathrm{~g} / \mathrm{L}$ & \\
& $\mathrm{ZnSO}_{4} \cdot 7 \mathrm{H}_{2} \mathrm{O}$ & $0.051 \mathrm{~g} / \mathrm{L}$ & \\
& $\mathrm{CuSO}_{4}$ & $0.09 \mathrm{~g} / \mathrm{L}$ & \\
& $\mathrm{H}_{3} \mathrm{MoO}_{4}$ or & $0.12 \mathrm{~g} / \mathrm{L}$ & \\
\hline$(\mathrm{pH} \mathrm{6.0} \mathrm{w/3} \mathrm{M} \mathrm{KOH})$ & $\mathrm{NaMoO}_{2} \cdot 2 \mathrm{KOH}_{2} \mathrm{O} \mathrm{M}^{2}$ & $163 \mathrm{~g} / \mathrm{L}$ & \\
\hline
\end{tabular}

\section{Acknowledgments}

This work benefited from a grant INSU-CNRS "Programme National de Recherche en Hydrologie (PNRH)" 99-PNRH-39 and support from Agropolis foundation.

\section{Competing interests}

The authors declare no conflict of interest.

\section{References}

1. Doussan, C., Pagès, L. and Vercambre, G. (1998). Modelling of the hydraulic architecture of root systems: An integrated approach to water absorption-Model description. Ann Bot 81:213223.

2. Doussan, C., Pierret, A., Garrigues, E. and Pagès, L. (2006). Water uptake by plant roots: IIModelling of water transfer in the soil root-system with explicit account of flow within the root system-Comparison with experiments. Plant Soil 283: 99-117.

3. Esser, H. G., Carminati, A., Vontobel, P., Lehmann, E. H. and Oswald, S. E. (2010). Neutron radiography and tomography of water distribution in the root zone. J Plant Nutr Soil Sci 173:757764.

4. Frensch, J. and Steudle, E. (1989). Axial and radial hydraulic resistance to roots of maize (Zea 
mays L.). Plant Physiol 91(2): 719-726.

5. Garrigues, E. (2002). Prélèvement hydrique par une architecture racinaire: imagerie quantitative et modélisation des transferts d'eau dans le système sol-plante. Ph. D. Thesis. Institut National Agronomique Paris-Grignon, Paris.

6. Garrigues, E., Doussan, C. and Pierret, A. (2006). Water uptake by plant roots: I-Formation and propagation of a water extraction front in mature root systems as evidenced by $2 \mathrm{D}$ light transmission imaging. Plant Soil 283: 83-98.

7. Glass, R. J., Steenhuis, T. S., Parlange, J. Y. (1989). Wetting front instability. 2. experimentaldetermination of relationships between system parameters and two-dimensional unstable flow field behavior in initially dry porous-media. Water Resour Res 25:1195-1207.

8. Granier, A. (1987). Evaluation of transpiration in a Douglas-fir stand by means of sap flow measurements. Tree Physiol 3(4): 309-320.

9. Hainsworth, J. M. and Aylmore, L. A. G. (1983). The use of computer-assisted tomography to determine spatial distribution of soil-water content. Aust J Soil Res 21(4): 435-443.

10. Hainsworth, J. M. and Aylmore, L. A. G. (1986). Water extraction by single plant roots. Soil Sci Soc Am J 50: 841-848.

11. Hignett, C. and Evett, S. (2002). Neutron thermalization. In: Methods of soil analysis. Dane, J. H. and Topp, G. C. (Eds.). SSSA book series 5: 501-520.

12. Javaux, M., Schröder, T., Vanderborght, J. and Vereecken, H. (2008). Use of a threedimensional detailed modeling approach for predicting root water uptake. Vadose Zone $\mathrm{J}$ 7:1079-1088.

13. Li, Y., Fuchs, M., Cohen, S., Cohen, Y. and Wallach, R. (2002). Water uptake profile response of corn to soil moisture depletion. Plant Cell Environ 25: 491-500.

14. Lobet, G. (2013). Regulation of water flow in the soil-root domain. Ph.D. thesis. Université Catholique de Louvain, Louvain la neuve.

15. Lobet, G. and Draye, X. (2013). Novel scanning procedure enabling the vectorization of entire rhizotron-grown root systems. Plant Methods 9(1): 1.

16. Lobet, G., Pages, L. and Draye, X. (2011). A novel image-analysis toolbox enabling quantitative analysis of root system architecture. Plant Physiol 157(1): 29-39.

17. Miyamoto, N., Steudle, E., Hirasawa, T. and Lafitte, R. (2001). Hydraulic conductivity of rice roots. J Exp Bot 52(362): 1835-1846.

18. Nakanishi, T. M., Okuni, Y. and Hayashi, Y. (2005). Water gradient profiles at bean plant roots determined by neutron beam analysis. J Radioanal Nucl Ch 264: 313-317.

19. North, G. B. and Nobel, P. S. (1995). Hydraulic conductivity of concentric root tissues of Agave deserti Engelm under wet and drying conditions. New Phytol 130: 47-57.

20. Pierret, A., Kirby, M. and Moran, C. (2003a). Simultaneous X-ray imaging of plant root growth and water uptake in thin-slab systems. Plant Soil 255(1):361-373.

21. Pierret, A., Doussan, C., Garrigues, E. and Mc Kirby, J. (2003b). Observing plant roots in their environment: current imaging options and specific contribution of two-dimensional approaches. 
Agronomie 23: 471-479.

22. Pierret, A., Gonkhamdee, S., Jourdan, C. and Maegh, J. L. (2013). IJ Rhizo: an open-source software to measure scanned images of root samples. Plant Soil 373: 531-539.

23. Pohlmeier, A., Oros-Peusquens, A., Javaux, M., Menzel, M. I., Vanderborght, J., Kaffanke, J., Romanzetti, S., Lindenmair, J., Vereecken, H. and Shah, N. J. (2008). Changes in soil water content resulting from Ricinus root uptake monitored by magnetic resonance Imaging. Vadose Zone J 7: 1010-1017.

24. Sanderson, J. (1983). Water uptake by different regions of the barley root Pathways of radial flow in relation to development of the endodermis. J Exp Bot 34: 240-253.

25. Schindelin, J., Arganda-Carreras, I., Frise, E., Kaynig, V., Longair, M., Pietzsch, T., Preibisch, S., Rueden, C., Saalfeld, S., Schmid, B., Tinevez, J. Y., White, D. J., Hartenstein, V., Eliceiri, K., Tomancak, P. and Cardona, A. (2012). Fiji: an open-source platform for biological-image analysis. Nat Methods 9(7): 676-682.

26. Schneider, C. L., Attinger, S., Delfs, J. O. and Hildebrandt, A. (2010). Implementing small scale processes at the soil-plant interface - the role of root architectures for calculating root water uptake profiles. Hydrol Earth Syst Sci 14: 279-289.

27. Srayeddin, I. and Doussan, C. (2009). Estimation of the spatial variability of root water uptake of maize and sorghum at the field scale by electrical resistivity tomography. Plant Soil 319: 185207.

28. Smit, A. L., Bengough, A. G., Engels, C., Noordwijk, M. van, Pellerin, S. and van de Geijn, S. C. (2000). Root methods: A handbook. Springer Pub. 594 p.

29. Tracy, S. R., Roberts, J. A., Black, C. R., McNeill, A., Davidson, R. and Mooney, S. J. (2010). The X-factor: visualizing undisturbed root architecture in soils using X-ray computed tomography. J Exp Bot 61(2): 311-313.

30. Varney, G. T. and Canny, M. J. (1993). Rates of water uptake into the mature root system of maize plants. New Phytol 123: 775-786.

31. Zappala, S., Mairhofer, S., Tracy, S., Sturrock, C. J., Bennett, M., Pridmore, T. and Mooney, S. J. (2013). Quantifying the effect of soil moisture content on segmenting root system architecture in X-ray computed tomography images. Plant Soil 370: 35-45. 